\title{
Flexible endoscopy of paediatric airways
}

\author{
F. Midulla*, J. de Blic ${ }^{\#}$, A. Barbato", A. Bush ${ }^{+}$, E. Eber ${ }^{\S}$, S. Kotecha ${ }^{f}$, E. Haxby**, C. Moretti ${ }^{\# \#}$, \\ P. Pohunek ${ }^{\text {बी }}$, F. Ratjen ${ }^{++}$
}

Flexible endoscopy of paediatric airways. F. Midulla, J. de Blic, A. Barbato, A. Bush E. Eber, S. Kotecha, E. Haxby, C. Moretti, P. Pohunek, F. Ratjen. (C) ERS Journals Ltd 2003.

ABSTRACT: Paediatric fibreoptic bronchoscopy is used for ever wider indications, and increasingly used in many contexts, including paediatric and neonatal intensive care.

The report of this Task Force contains an overview on the current applications of paediatric bronchoscopy. The report discusses the facilities and equipment needed for the procedure, including the newly developed bronchoscopes which are allowing intervention even in very small children. The indications of both flexible and rigid bronchoscopes in the context of newer and smaller flexible endoscopic equipment are also considered. The care of the instruments, including disinfection and sterilisation, is fully documented. Patient management is described, including the relative merits of conscious sedation and general anaesthesia, as well as special settings for the procedure, including the needs in intensive care.

Special procedures, increasingly performed bronchoscopically are described. These include bronchoalveolar lavage, endobronchial and transbronchial biopsy, laser therapy, bronchography, and endoscopic intubation and drug therapy. Finally, neonatal bronchoscopy is discussed, and the ethics of bronchoscopic procedures, including bronchoscopic research in children.

Advances in instrumentation, and also improved anaesthetic techniques, allow fibreoptic bronchoscopy to be safely performed in even very small, sick infants, provided proper precautions are taken.

Eur Respir J 2003; 22: 698-708.
* Istituto di Clinica Pediatrica, Servizio Speciale Fibrosi cistica, Università di Roma "La Sapienza", Roma, Italy. " Service de Pneumologie et d'allergologie pediatriques, Groupe Hospitalier Necker-Enfants malades, Paris, France. "Dept of Paediatrics, University of Padova, Padova, Italy, ${ }^{+}$Dept of Paediatrics, Royal Brompton Hospital, London, UK. ${ }^{\S}$ Universitaetsklinik fuer Kinder und Jugendheilkunde, Klinische Abteilung fuer Pulmonologie und Allergologie, Graz, Austria. ${ }^{f}$ Dept of Child Health, University of Leicester, Leicester, UK. **Dept of Anaesthesia, Royal Brompton Hospital, London, UK. ${ }^{\text {\#\# Istituto }}$ di Clinica Pediatrica, Servizio Neonatologia, Università di Roma "La Sapienza", Roma, Italy. "Division of Paediatric Pulmonology, 2nd Paediatric Dept, University Hospital Motol, Praha, Czech Republic. ${ }^{+}$Children's Hospital, University of Essen, Essen, Germany.

Correspondence: F. Midulla, Servizio Speciale Fibrosi Cistica, Università di Roma "La Sapienza", Viale Regina Elena 324, 00161 Rome, Italy. Fax: 390649979266

E-mail:midulla@uniroma1.it

Keywords: Bronchoalveolar lavage, children, flexible bronchoscopy, foreign body, neonatal intensive care, paediatric intensive care

Received: December 62002

Accepted after revision: March 262003

\section{CONTENTS}

Indications for bronchoscopy . . . . . . . . . . .6999

Bronchoscopy in an intensive care setting. . . . . .700

Neonatal bronchoscopy . . . . . . . . . . .700

Special procedures. . . . . . . . . . . . . 701

Bronchoalveolar lavage . . . . . . . . . . . . .701

Endobronchial biopsy . . . . . . . . . . . . .701

Transbronchial biopsy. . . . . . . . . . . . . 701

Laser . . . . . . . . . . . . . . . . . . . . 702

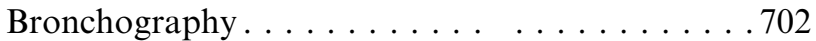

Endoscopic intubation. . . . . . . . . . . . .702

Drug application. . . . . . . . . . . . 702

Closure of bronchopleural fistulae . . . . . . . .702

Contraindications to bronchoscopy . . . . . . .702

Ethical aspects of bronchoscopy . . . . . . . . 702

Patient management . . . . . . . . . . . .702

Prebronchoscopic procedures . . . . . . . . . . 702
Complications and their management . . . . . . . .704

Recovery and post-procedure care . . . . . . . . . .704

Bronchoscopy suite . . . . . . . . . . . . . .704

Bronchoscopy room . . . . . . . . . . . . . . . . 704

Personnel . . . . . . . . . . . . . . . . . . . . 705

Equipment . . . . . . . . . . . . . . . 705

Mobile bronchoscopy unit . . . . . . . . . . .705

Equipment storage area . . . . . . . . . . . . .705

Cleaning and disinfection . . . . . . . . . . 705

Cleaning and disinfection area . . . . . . . .705

Cleaning. . . . . . . . . . . . . . . . . . . . .706

Disinfection . . . . . . . . . . . . . . . . . . 706

Sterilisation . . . . . . . . . . . . . 706

Summary and conclusions $\ldots \ldots \ldots \ldots \ldots \ldots 706$

$\overline{\text { For editorial comments see page } 576 .}$ 
Flexible endoscopy of the paediatric airway includes examination of the nose, pharynx, larynx and tracheobronchial tree and was first reported in children 23 yrs ago [1]. Since then, the technique has improved and continued to develop and the indications, methods, diagnostic utility and safety of this procedure have been described [2-5]. Ever smaller models of paediatric flexible bronchoscopes have become available in recent years, creating opportunities for applications that had hitherto been unthinkable [6-9], for example a $2.7 \mathrm{~mm}$ external diameter steerable fibreoptic bronchoscope with a $1.2 \mathrm{~mm}$ suction channel, which can be used in all but the smallest preterm babies. Modern anaesthetic techniques have also rendered the examination of small and very sick infants much safer than before.

Hence, in view of the rapid advances in this field, this Task Force provides new guidelines for paediatric flexible bronchoscopy (FB). The guidelines aim to benefit practitioners of paediatric FB by outlining principles that enhance the safety of, maximise effectiveness and clarify the indications for the procedure.

\section{Indications for bronchoscopy}

FB is indicated when the benefits outweigh its risks and when it is the best way to obtain diagnostic information. The decision to perform FB in children should always be made on an individual basis after consideration of the patient's history, physical examination, and the results of previous diagnostic tests. FB can be performed for diagnostic and therapeutic purposes or in order to obtain secretions and cells from the lungs (table 1) [10]. FB is generally contraindicated for the removal of endobronchial foreign bodies, treatment of massive haemoptysis, and in the diagnosis of acute epiglottitis [11].

Indications for diagnostic bronchoscopy vary with the age of the patient. In children a normal bronchoscopic examination can be of great value; the definitive exclusion of suspected problems (for example foreign body aspiration) may be as important as a specific finding. The diagnostic yield of FB can be increased by the information obtained with bronchoalveolar lavage (BAL) and biopsy of the mucosa. The evaluation of airways obstruction, which may involve the

Table 1. - Indications for paediatric flexible bronchoscopy

Airway obstruction
Stridor/noisy breathing
Persistent/recurrent wheezing
Radiographic abnormalities
Atelectasis
Recurrent/persistent consolidations
Atypical and unknown infiltrates
Localised hyperinflation
Chronic cough
Suspected foreign body aspiration
Haemoptysis
Evaluation of the artificial airway
Therapeutic bronchoscopy
Restoration of airway patency
Mucus plugs or blood clots
Alveolar filling disorders (alveolar proteinosis, lipid pneumonia)
Special procedures
Bronchoalveolar lavage
Brushing or biopsy of the bronchial mucosa
Biopsy of endobronchial lesions
Transbronchial biopsy
Administration of drugs
Endoscopic intubation

upper or lower airway or both, is the most common indication for FB in children. Stridor or noisy breathing, that usually reflects an obstruction of the upper airways, is the most common indication for FB in infants. Since most of the time the flexible instrument is passed through the nose, it allows the examination of the adenoids, and the larynx and hypopharynx in the most physiological conditions and often when the stridor is audible. This gives the opportunity to study the laryngeal structure and function during inspiration and expiration. Laryngomalacia is the most common congenital laryngeal anomaly and the most frequent cause of persistent stridor in children. Other congenital anomalies of the larynx causing stridor are: laryngoceles and saccular cysts, laryngeal webs and atresia, laryngotracheal stenosis, laryngeal and tracheal clefts, congenital neoplasms such as hemangiomas, bifid epiglottis and ventral cleft of the larynx [12]. Laryngeal cleft may be missed by $\mathrm{FB}$, and rigid bronchoscopy performed if this diagnosis is seriously considered. Paralysis of the vocal cords is the third most common congenital laryngeal anomaly producing stridor in infants and children and it is usually the result of congenital anomalies of the central nervous system. Insufficient information exists on the frequency of concomitant abnormalities, because both the underlying population and the indications for bronchoscopy vary greatly. Nevertheless, abnormalities below the epiglottis were found in up to $68 \%$ of cases [13]. Therefore, if possible, it is important to inspect both the upper and lower airways in any case of airway endoscopy. While airway endoscopy is not necessarily indicated in every infant with stridor, it should be performed in any child with severe or persistent symptoms, if associated with hoarseness or if it leads to oxygen desaturation or apnoea. Stridor in older children is rare but, if not due to recent endotracheal intubation, is always an indication for endoscopy of the airways.

Persistent/unexplained wheezing that does not respond to bronchodilator and anti-inflammatory therapy is another clinical indication for FB, mainly in infants. It is often caused by congenital malformations of the tracheo-bronchial tree such as primary tracheomalacia and bronchomalacia, stenosis and webs of the trachea, tracheomalacia or bronchomalacia secondary to vascular compression, tracheo-esophageal fistula or esophageal atresia, enlargement of the left atrium or congenital cysts [12]. Localised monophonic wheeze may be present in a child with foreign body aspiration. There are no controlled studies on the indications of flexible endoscopy in the literature, but airway abnormalities were found in $>50 \%$ of cases in one series [13]. It should be noted that FB is superior to rigid bronchoscopy in the assessment of airway dynamics, because less positive end expired pressure is applied during the examination.

A variety of radiographic anomalies represent important indications for FB in children. Recurrent/persistent atelectasis, recurrent pneumonia, persistent pulmonary infiltrates or mass lesions are radiological indications for bronchoscopy. Undetected foreign body aspiration, anatomic abnormalities and mucus plugs are commonly found. In these situations, it is also very important to perform BAL in order to obtain pulmonary samples for microbiological studies and to try to exclude clinical situations such as aspiration and interstitial lung diseases. Localised hyperinflation may be the result of partial bronchial obstruction and can be the consequence of foreign body aspiration, extrinsic bronchial compression and localised bronchomalacia.

Chronic cough (atypical and persistent) in a patient with normal imaging, functional studies and haematological examinations, and that does not respond to medical therapy is another indication for flexible endoscopy in children. Foreign body aspiration and congenital malformation should 
be excluded. A BAL should be performed to try to rule out conditions such as microaspiration [14].

Suspected foreign body aspiration can be excluded with FB, but foreign body extraction in children should be performed with the rigid bronchoscope [15]. Haemoptysis is a relatively uncommon indication for diagnostic bronchoscopy in children. However, haemoptysis associated with a clear episode of pneumonia should be evaluated with bronchoscopy in order to exclude the presence of a foreign body, malignancy or vascular malformation. Evaluation of an artificial airway (tracheostomy or endotracheal tube) is a common indication for diagnostic bronchoscopy. Flexible bronchoscopes of appropriate size can be passed through the endotracheal tube or the tracheotomy in order to evaluate the patency or the position of the tube. Diagnostic flexible endoscopy is also indicated in infants and children with obstructive apnoea.

The diagnostic yield for FB will depend on the population studied, and the previous investigation and treatment performed. For example, the highest yields for BAL in the immunocompromised host will be before empirical treatment is started, and in patients not receiving prophylaxis for Pneumocystic carinii. There are no internationally agreed guidelines on the expected diagnostic yield for the procedure. Furthermore, in assessing figures of diagnostic yield of an examination, it is important to differentiate diagnoses that are of importance to the child, and findings of mere curiosity value which do not alter management.

The indications for therapeutic FB primarily involve the restoration of airway patency. Mucus plugs or blood clots in the airways causing atelectasis can be removed with the flexible bronchoscope. Most mucus plugging can be cleared by $\mathrm{FB}$; just occasionally, rigid bronchoscopy is needed to remove large resistant plugs. Patients with alveolar filling disorders, such as alveolar proteinosis or lipid aspiration may benefit from BAL through a flexible bronchoscope [16].

Finally, FB can be used in order to perform special procedures such as biopsy of endobronchial lesions, biopsy and brushing of bronchial mucosa, transbronchial biopsy, bronchoscopic intubation and BAL. It is also a tool to administer drugs such as surfactant or deoxyribonuclease (DNase) [17].

\section{Bronchoscopy in an intensive care setting}

Airway problems may have been the primary reason for admission to the paediatric intensive care unit (PICU), or arisen as a secondary complication of another illness. Children in PICU may pose particular problems in that they may be ventilator dependent, have haemodynamic instability or a coagulopathy. Children who are not intubated should be managed as indicated above although it may be desirable to transfer them to theatre for the procedure to be undertaken under general anaesthesia [18].

In children who are intubated and ventilated full monitoring should be instituted if not already in place. In order to facilitate the procedure, it may be necessary to alter the method of airway maintenance from an endotracheal tube to a laryngeal mask or facemask. Occasionally an endotracheal tube of larger diameter is needed. Especially in PICU, an observer trained in airway skills should be available throughout the procedure to monitor the child. In an unstable child, it is wise for this observer to limit the length of time the bronchoscope is down the airway. It may be better to complete the examination by doing a series of short inspections, rather than one prolonged procedure. Sedation should be increased appropriately and muscle relaxants given if indicated.

It may be advisable to perform arterial blood gas analysis prior to the procedure so that the baseline gas exchange can be documented. In most instances hand ventilation via an Ayre's T-piece is preferable with constant observation of chest movement. In small children the bronchoscope may occupy most of the endotracheal tube diameter which will increase airway resistance, reduce ventilation leading to hypercapnia and also produce significant levels of positive end-expiratory pressure (PEEP), the last two of which can cause respectively a rise in pulmonary vascular resistance and a fall in cardiac output. Hypoxia is common particularly during BAL [19]. Following the procedure there may be a period of instability when ventilation requirements are increased and gas exchange is poor. Further blood gas analysis and chest radiography may need to be performed. In the child who has been extubated or decannulated as a result of the bronchoscopy, very close observation of respiratory parameters should be continued for several hours.

\section{Neonatal bronchoscopy}

With the availability of neonatal bronchoscopes with an outer diameter as little as $2.2 \mathrm{~mm}$, it is not surprising that there is considerable interest in direct visual assessment of the neonatal airway. As the most extreme preterm infants survive the neonatal course, albeit at the expense of prolonged periods of mechanical ventilation and oxygen therapy, the indications for airway assessment have also increased [5].

Most of the indications are directed towards diagnosis and assessment of the airways and of severity of the abnormalities. The newer flexible bronchoscopes have an improved suction channel and more therapeutic manoeuvres may be possible including aspiration of mucous plugs, instillation of drugs and satisfactory BAL. At the Hôpital des Enfants Malades in Paris, France, for 201 bronchoscopies in infants performed between January 1982 and January 1992, the most common indications were persistent atelectasis $(n=77,38 \%)$, unexplained episodes of cyanosis $(\mathrm{n}=23,11 \%)$, unexplained respiratory distress $(n=20,10 \%)$, stridor $(n=14,7 \%)$ and the remainder were for acute atelectasis, assessment of lung malformations and repeat bronchoscopies for re-assessment of the airways [5]. The Paris neonatal experience is that in 79 infants with chest radiograph abnormalities only 15 $(19 \%)$ had normal findings with $22(28 \%)$ having either tracheal or bronchial stenosis, $7(9 \%)$ had granuloma, 10 $(13 \%)$ had vascular compression, the remainder had tracheo or bronchomalacia, hypersecretion and in one case, an unsuspected foreign body [5]. Clearly, the indications are wide ranging as with older children, but the information obtained may be of great importance to the management of the infant. This is of particular importance when abnormalities of the upper airway including subglottic stenosis compromise the respiratory status of the child such that extubation from mechanical ventilation is hindered. The technique of blind insertion of a catheter remains the method of choice for obtaining lung secretions for microbiology as it is simple to perform and minimises the compromise to the infant.

For more mature infants who are stable and are assessed on an outpatient basis, the procedure described above for older children can be adapted for the infant. However, particular attention is paid to sedation and analgesia and comfort of the child. Although a combination of intravenous sedation and analgesia has been commonly used, a general anaesthetic has advantages in that an experienced anaesthetist constantly monitors the airway. 
Inspection of the lower airway should always be performed after local anaesthesia of the larynx and sedation or general anaesthesia of the neonate. Local anaesthetic such as $2 \%$ lidocaine should be used for spraying the vocal cords. It cannot be stressed often enough that the infant must be monitored closely for any deterioration. Heart rate, oxygen saturation, blood pressure and temperature must be monitored constantly. The bronchoscope can be inserted per nasally, through a laryngeal mask or through the tracheostomy port.

For the severely ill infant in the neonatal intensive care setting who is requiring mechanical ventilation for respiratory failure, the risks of complications are significantly increased. These babies are especially prone to hypothermia and therefore a warm environment and attention to the infant's temperature is essential. In ventilated infants, analgesia with opiates such as diamorphine or fentanyl is commonly used. Sedation is rarely used and when it is used it is usually a benzodiazepene such as midazolam. The airway of the sick preterm infant is readily compromised with the introduction of an instrument that almost completely blocks the endotracheal tube. Video recording of the procedure is therefore necessary. The bronchoscope can be inserted and withdrawn within $10-45 \mathrm{~s}$ as tolerated by the infant and the video recording can be reviewed more closely for an accurate assessment of the findings. Close inspection of the subglottic space is essential as this is often difficult to assess given the wide angle of a flexible bronchoscope.

After the procedure the infant remains at risk of complications and requires close monitoring. Apneas, hypoxia and bradycardia are common and thus need to be sought and treated. For mechanically ventilated infants, blood gases are essential and the ventilatory parameters altered accordingly. Since any pre-existing laryngeal oedema may be exacerbated by the procedure, the infant may require treatment with a short course of corticosteroid.

\section{Special procedures}

Several special procedures can be performed even in small preterm infants through the working channel of the flexible bronchoscope. Interventional bronchoscopy however, is better performed using rigid bronchoscopes.

\section{Bronchoalveolar lavage}

This technique was the focus of a separate Task Force of the European Respiratory Society [20].

\section{Endobronchial biopsy}

Endobronchial biopsy is a safe procedure for the diagnosis of tuberculosis and other infectious or granulomatous disorders. It is also a well-established clinical technique for obtaining ciliated cells for the diagnosis of primary ciliary dyskinesia. Research applications for endobronchial mucosal biopsies include studies on bronchial inflammation in patients with asthma or cystic fibrosis [6, 8, 9, 21, 22]. Biopsy of superficial airway structures can be performed with a brush or forceps [22]. The 4.9 or $5 \mathrm{~mm}$ instrument with its $2.2 \mathrm{~mm}$ working channel allows a protected brush to be used. In contrast, for the endoscopes $<3.6 \mathrm{~mm}$ only unsheathed brushes may be used. When such a brush is pulled back through the working channel cells may be lost. This risk can be minimised when the brush is left protruding from the bronchoscope or even better is hidden in the tip of the scope while the instrument is withdrawn. Subsequently, agitating the brush in appropriate medium dislodges the cells. Biopsies should be taken from segmental subcarinas, which are sharper and thus allow a better grip by the forceps. A routine chest radiograph is not necessary after endobronchial biopsy. The material can be prepared for electron microscopy and immunohistochemistry as well as standard histopathology.

\section{Transbronchial biopsy}

Transbronchial biopsy (TBB) is a technique to obtain peripheral lung tissue for diagnostic studies including histopathological examination and for microbial cultures. TBB has an established place in lung transplant recipients: it has a high sensitivity and specificity, and represents the gold standard for diagnosing acute rejection and delineating opportunistic infection [23]; it is of less use in diagnosing chronic rejection (bronchiolitis obliterans) [24]. In contrast, it plays a more controversial role in patients with human immunodeficiency virus (HIV) infection to delineate noninfective pulmonary pathology, after bone marrow transplantation to diagnose obliterative bronchiolitis, and in patients with interstitial lung disease [25].

A plain chest radiograph, a full blood count including platelet count, and a coagulation screen should be performed prior to TBB. The procedure is carried out under deep sedation or general anaesthesia. Fluoroscopy is mandatory for accurate positioning of the biopsy forceps in order to get the maximum yield from sites of radiographic abnormality and to minimise the risk of pneumothorax. The forceps (either alligator jaw or cupped head biopsy forceps) are introduced through the bronchoscope and advanced under fluoroscopic screening until resistance is felt. Then the forceps are withdrawn 1-2 cm, the jaws of the forceps are opened and wedged into the lung tissue after rapidly advancing; some workers do so after advancing and withdrawing the forceps for two to three times. Subsequently, the forceps are closed and briskly withdrawn. After completion, a small saline lavage and visualisation of the bronchial tree should be performed to ensure haemostasis. A chest radiograph 2-4 h later is mandatory to rule out a slowly developing pneumothorax. Only one lung should be sampled on a same occasion in order to prevent the occurrence of bilateral pneumothoraces. The middle lobe and the lingula are avoided if at all possible to reduce the risk of pneumothorax. At least three biopsies should be obtained for microbiological and histological studies. In order to achieve optimal specimens, the application of negative pressure during fixation of the biopsy is recommended [26]. However, especially in children $<2$ yrs, it may be difficult to obtain specimens containing sufficient lung parenchyma. To circumvent this problem in infants and small children, a new technique has been developed [26]. With this "indirect" technique, a $2.2 \mathrm{~mm}$ bronchoscope is used to direct a plastic catheter visually into the desired lung segment. Subsequently, the suction catheter acts as the working channel through which larger biopsy forceps can be introduced. However, experience with this technique is limited.

The major complication of TBB is a pneumothorax with an incidence of $\sim 3 \%$. Small haemorrhages often occur but resolve either spontaneously or after lavage with saline. If bleeding is profuse and persistent; instillation of adrenalin solution $(1: 10,000)$ may be necessary. Other complications include transient pyrexia and transient dyspnoea. Thus, it is recommended that patients should be observed overnight following the procedure. 


\section{Laser}

Usually, rigid bronchoscopes are used to perform endoscopic laser resection. However, airway lesions such as acquired tracheal or bronchial stenosis can be successfully managed even in infants with laser treatment using flexible endoscopes $[27,28]$. There are some drawbacks of the latter technique compared to rigid bronchoscopy: 1) the procedure is more time-consuming, 2) the inability to perform mechanical resection may result in incomplete resolution of the obstruction and may necessitate more laser energy to vaporise the lesions, 3) complications such as bleeding are difficult to control, and 4) flexible endoscopes are easily damaged.

\section{Bronchography}

Bronchography can be performed by injecting contrast material through the working channel of the flexible bronchoscope in order to delineate anatomic abnormalities [29]. The flexible instruments can be situated in the area of interest, thus less contrast material is needed. In addition, some of the contrast can be suctioned back at the end of the procedure, thus decreasing the risks of atelectasis and chemical pneumonitis.

\section{Endoscopic intubation}

Intubation of a difficult airway may be accomplished with the aid of a flexible bronchoscope even in preterm neonates (e.g. in patients with Pierre Robin syndrome, craniofacial trauma) [30]. With ultrathin instruments, intubation may be performed with endotracheal tubes as small as $2.5 \mathrm{~mm}$.

\section{Drug application}

Bronchoscopic administration of surfactant may represent an effective method of delivery in acute respiratory distress syndrome [31]. Furthermore, in persistent atelectasis unresponsive to medical therapy bronchoscopic instillation of recombinant human DNase has been found to be useful [17].

\section{Closure of bronchopleural fistulae}

FB with the delivery of methacrylate adhesive to a bronchopleural fistula may be a reasonable alternative to operative closure when the operative risk is great [32]. As the glue should not come into direct contact with the bronchoscope, it should be injected through a catheter placed through the working channel of the instrument.

\section{Contraindications to bronchoscopy}

The only absolute contraindication is that the procedure will elicit no information of value. Relative contraindications include pulmonary hypertension, baseline hypoxia and uncorrected bleeding diathesis [10, 33]. Fibreoptic bronchoscopy is not indicated to attempt to remove a foreign body. Although it has been suggested that flexible bronchoscopy should precede a rigid bronchoscopy to localise the foreign body and guide the surgeon with the rigid bronchoscope, this is not a widely held view.

\section{Ethical aspects of bronchoscopy}

Bronchoscopy is unethical in a clinical context unless performed with the maximum attention to safety, and in a context in which the potential benefit to the child justifies the perceived risk of the examination. Fully informed consent, in accord with local and national guidelines, is mandatory. The ethics of research bronchoscopy have recently been debated [34-36]. In general, the performance of a bronchoscopy cannot be considered to be of such low risk that it is justified to perform it on a child for research purposes alone [37]. However, if a clinically indicated bronchoscopy is performed, then it is fully justifiable to use clinically gathered material (e.g. BAL fluid, endobronchial biopsy material) for research purposes, provided informed consent has been obtained from the family and age-appropriate assent from the child [38]. It may also be legitimate to prolong the procedure for a short time to make extra measurements, for example endobronchial $\mathrm{pH}$ [39]. It must be strongly urged that it is mandatory for any investigator contemplating using bronchoscopy in part for research to submit an application to their Institutional Ethical Review body, and to ensure that such research is conducted to the highest possible ethical and scientific standards, without compromising the safety, dignity and rights of the child.

\section{Patient management}

The selection of the most appropriate anaesthetic or sedation technique is determined by the indications for the procedure. The most important step in planning a paediatric bronchoscopy is to decide what question needs to be answered by the procedure. This will determine what bronchoscope is used and how the child should be sedated or anaesthetised. The available techniques are: 1) sedation (child by definition spontaneously breathing); 2) general anaesthesia (depending on the needs of the procedure, child may or may not be spontaneously ventilating).

\section{Prebronchoscopic procedures}

The child may be admitted either as a day case or as an inpatient depending on the likelihood of complications or if other investigations need to be performed. Both the bronchoscopist and the anaesthetist should obtain a full history and perform a complete physical examination. Written, fully informed consent should be obtained by a senior doctor. The family (and child when age appropriate) should be given full information about the procedure prior to admission. This should include the risks of the procedure in the hands of the particular bronchoscopist, and the likelihood that a particularly high-risk child may need postbronchoscopy care in an intensive care or high dependency unit. The likely way that anaesthesia or sedation will be induced and the need for intravenous access should also be discussed.

Fasting prior to the procedure is usually $4-6 \mathrm{~h}$ for milk and solids, or $3 \mathrm{~h}$ for water. In general, if adequate explanation is given, it is unnecessary to administer sedative premedication as this may delay post-procedure recovery. However if the child is distressed or unable to cooperate then premedication is advisable. Oral atropine $\left(0.01-0.02 \mathrm{mg} \cdot \mathrm{kg}^{-1}\right)$ minimises bradycardia induced by vagal stimulation and also decreases airway secretions [40]. However, the need for premedication, and the choice of agent, is the prerogative of the individual anaesthetist, and it would be wrong to issue mandatory guidelines. Topical anaesthesia is of a particular importance 
Table 2. - Main drugs used for sedation for paediatric flexible bronchoscopy (note that these doses are a guide only, and the agents should only be administered by qualified personnel)

\begin{tabular}{|c|c|c|c|c|c|}
\hline Drug & Action & Dose & Onset of action min & Duration min & Antagonist \\
\hline Midazolam & $\begin{array}{l}\text { Anxiolysis } \\
\text { Amnesia }\end{array}$ & IV: $75-300 \mathrm{mcg} \cdot \mathrm{kg}^{-1}$ & $1-5$ & 90 & $\begin{array}{l}\text { Flumazemil } \\
\quad 0.01 \mathrm{mg} \cdot \mathrm{kg}^{-1}\end{array}$ \\
\hline Meperidine & Analgesia & IV: $0.5-2 \mathrm{mg} \cdot \mathrm{kg}^{-1}$ & 5 & $180-240$ & $\begin{array}{l}\text { Naloxone } \\
\quad 0.01 \mathrm{mg} \cdot \mathrm{kg}^{-1}\end{array}$ \\
\hline Ketamine & $\begin{array}{l}\text { Analgesia } \\
\text { Amnesia }\end{array}$ & $\begin{array}{l}0.25-0.5 \mathrm{mg} \cdot \mathrm{kg}^{-1} \\
\text { intermittent IV bolus }\end{array}$ & $2-4$ & $10-20$ & \\
\hline Propofol & Deep sedation & $\begin{array}{l}\text { Intermittent bolus } \\
\text { dose } 0.5-1 \mathrm{mg} \cdot \mathrm{kg}^{-1} \\
\text { Continuous infusion: } \\
100 \mathrm{mcg} \cdot \mathrm{kg}^{-1} \cdot \mathrm{min}^{-1}\end{array}$ & $<1$ & 30 & \\
\hline Remifentayl & $\begin{array}{l}\text { Deep sedation } \\
\quad \text { (to suppress cough) }\end{array}$ & $\begin{array}{l}\text { IV } 0.1-0.25 \mathrm{mcg} \cdot \mathrm{kg}^{-1} \cdot \mathrm{min}^{-1} \\
\text { Continuous infusion } \\
0.05 \mathrm{mcg} \cdot \mathrm{kg}^{-1} \cdot \mathrm{min}^{-1}\end{array}$ & $2-5$ & $2-3$ & \\
\hline
\end{tabular}

when conscious sedation is used. Lidocaine $2-5 \%$ is applied on the nose and the larynx and $0.5-1 \%$ below the larynx. Lidocaine may be instilled directly, sprayed or nebulised (3-5 $\mathrm{ml}$ of $2-4 \%$ lidocaine). The total dose should not exceed 5-7 mg $\mathrm{kg}^{-1}$ but the exact amount applied is difficult to assess as most of lidocaine is removed by suction, spitting or swallowing. Insufficient topical anaesthesia will result in pain, cough, laryngospasm or bronchospasm due to vagal stimulation. A further consideration is the possible effect of local anaesthetic agents on the larynx. In a study of 156 infants bronchoscoped under sedation with midazolam and nalbuphine, a topical anaesthetic, falsely resulted in the appearances of laryngomalacia, namely arytenoids collapse and epiglottal folding. The authors suggested that the larynx should be examined from above before topical anaesthesia is applied [41].

Oxygen supplementation during the procedure is mandatory in young infants and children especially those with poor respiratory status. Supplemental oxygen can be delivered with a naso-pharyngeal prong through one nostril with the bronchoscope passed down the other or by a facemask over the nose and mouth.

FB may induce anxiety, fear and pain. As no single agent adequately provides anxiolysis, analgesia and amnesia, a combination of drugs is most often used. The available techniques are conscious and general anaesthesia (deep sedation). Conscious sedation and analgesia describe a state that allows patients to tolerate "unpleasant" procedures while maintaining adequate cardio-respiratory function and the ability to respond purposefully to verbal commands and tactile stimulation [42-44]. The Joint Commission on Accreditation of Healthcare Organizations has mandated that children who undergo sedation for procedures must receive the same standard of care as those who undergo general anaesthesia [42]. Table 2 lists some agents, which are often used to induce conscious sedation. There is no unique protocol to induce conscious sedation. It is probable that combinations of agents (for example intravenous midazolam and inhalation of nitrous oxide and oxygen, or intravenous midazolam and intravenous meperidine or remifentanil) may be more effective than single agents. However, published data suggest that drug combinations may increase the likelihood of adverse outcomes [45]. Anxiolysis and analgesia may also be achieved with nitrous oxide ( $50 \%$ nitrous oxide in oxygen) administered via a facemask [46]. If sedation is used it should be given in small incremental doses until the desired effect is observed.

General anaesthesia with spontaneous breathing or with complete loss of consciousness (defined by failure to respond to verbal command or to tactile stimulation) is achieved by drugs administered by a person trained in anaesthesiology [42]. General anaesthesia may be achieved either by intravenous drugs (propofol, ketamine, sulfentanyl or remifentanyl) or by volatile agents (sevofluorane) either used alone or in combination. During general anaesthesia, the airway and ventilation should be maintained by one of the following methods (table 3): 1) during general anaesthesia with spontaneous breathing, a facemask is used to deliver oxygen. The bronchoscope is passed through an adaptor on the facemask.

Table 3. - Techniques to ensure adequate ventilation during anaesthesia for paediatric flexible bronchoscopy

\begin{tabular}{lll}
\hline Technique & \multicolumn{1}{c}{ Advantages } & \multicolumn{1}{c}{ Disadvantages } \\
\hline Facemask & $\begin{array}{l}\text { Inspect entire airway } \\
\text { Assess airway dynamics/malacia } \\
\text { Does not limit size of bronchoscope } \\
\text { Easy to pass tube } \\
\text { Inspect most of upper airway } \\
\text { Assess airway dynamics/malacia } \\
\text { Does not limit size of bronchoscope } \\
\text { Easy to position mask }\end{array}$ & $\begin{array}{l}\text { Probably the most technically } \\
\text { challenging for the anaesthetist } \\
\text { Laryngospasm may be a problem } \\
\text { Possibly less good upper airway access } \\
\text { Laryngospasm in spontaneously } \\
\text { ventilating child }\end{array}$ \\
& & Airway control suboptimal \\
Laryngeal mask & & Cannot assess upper airway \\
& Cannot assess vocal cord movement \\
& May limit size of bronchoscope \\
Endotracheal intubation & Cannot assess airway dynamics/malacia \\
& Decure airway anaesthesia safe & Cannot assess upper airway \\
Cannot assess vocal cord movement & May limit size of bronchoscope
\end{tabular}


This method permits application of PEEP. 2) As above, a nasopharyngeal prong can be passed through one nostril and the bronchoscope passed down the other. 3) A laryngeal mask can be used in all children. Care is required in those with the most severe respiratory distress. The technique precludes examination of the upper airway [47]. 4) Endotracheal intubation is only used if a general anaesthetic has been given. It allows maximum control of the airway, but may limit the extent of examination and the size of the bronchoscope which can be used.

In general, the majority of flexible bronchoscopies can be performed under sedation that preserves spontaneous ventilation. Assessment of the airway during spontaneous ventilation is essential to diagnose dynamic airway compression as well as alterations in vocal cord movement. Therefore, the choice between anaesthesia and sedation depends both upon the patient's clinical status and the indication for the procedure.

\section{Complications and their management}

Most of the life-threatening adverse events involve drug overdose, inadequate monitoring or inappropriate sedation [48]. Upper airway pathology, persistent radiographic changes, oxygen dependency and a weight $<10 \mathrm{~kg}$ are major risk factors associated with adverse events [49].

Partial or total airway obstruction by the bronchoscope and depression of respiratory drive by sedation are the most frequent causes of oxygen desaturation in children [43]. Respiratory depression is the most concerning adverse effect of sedation [43]. In children undergoing bronchoscopy, when the airway is compromised by both the underlying condition and the procedure itself, any depressant effect of sedation is likely to be poorly tolerated. Oxygen supplementation may delay detection of reduced ventilation but this should be sought by close observation of the child, and capnography where appropriate [50].

Oxygen desaturation has been reported to be more frequent in younger infants [48-50]. Falls in oxygen saturation are common particularly whilst the bronchoscope is in the midtrachea and can occur despite oxygen supplementation [41]. However, there is a decreased incidence and severity of hypoxia if oxygen is administered during procedures undertaken using sedation [50]. In a series of bronchoscopies in children $<10 \mathrm{~kg}$, hypoxia was common even during oxygen administration, necessitating increasing the fraction of inspired oxygen [49].

Other reported complications during the procedure are rare, in general occurring in $<5 \%$ of procedures. Minor complications include epistaxis, airway bleeding, excessive cough, and transient laryngospasm. Major complications include apnoea, bradycardia and important oxygen desaturation $\left(\mathrm{Sa}, \mathrm{O}_{2}<90 \%\right)$ either isolated or secondary to laryngospasm or bronchospasm $[50,51]$. Post procedure atelectasis is another possible complication. Few paediatric fatalities have been reported $[11,52-53]$. Spread of infections seems to be a very rare complication [54].

\section{Recovery and post-procedure care}

On completion of the procedure, the child should be awakened whilst still fully monitored. Monitoring of oxygen saturation should continue during the recovery period. An intravenous line should be left in situ until the child is fully awake and tolerating oral fluids. Late complications are rare, but have been described, including progressive stridor necessitating intubation [41]. The sedated child should never be left unobserved and may require the same formal recovery facilities as after a general anaesthetic. Sedative drugs may have a hangover effect lasting several hours and the child should be monitored throughout this period [45]. The child should remain in the recovery area until cardiovascular and respiratory stability are assured and the patient is awake and orientated. If local anaesthetic agents have been applied to the airway then laryngeal reflexes may be depressed for up to an hour after the procedure. Children should not drink during this period as the risk of aspiration may be increased.

\section{Bronchoscopy suite}

Any dedicated bronchoscopy suite should include space for patient preparation and recovery, a procedure area and a cleaning and maintenance area. The size and arrangement of the suite will depend on the number and types of bronchoscopies performed in the particular institution. However, FB does not require a surgical operating room or dedicated facility and can be safely performed in many different areas, for example a side room on a ward, an intensive care unit, fluoroscopy lab or neonatal ward, if adequate mobile equipment is available. Wherever the procedure is performed, it is essential that the child can be safely sedated or anaesthetised, and adequately monitored (see Patient Management section). The bronchoscopy suite should include space for patient preparation and recovery, a procedure area and a cleaning and maintenance area. The size and arrangement of the bronchoscopy suite will depend on the number and type of bronchoscopies performed in the particular institution.

\section{Bronchoscopy room}

The pre-bronchoscopy preparation area will differ according to the type of anaesthesia or sedation used. However, even if all the administration of sedation and local anaesthesia takes place in the procedure room, a separate room where the patient can wait for the procedure in privacy with his or her parents or guardians should also be available.

In the procedure room there should be enough space around the patient to permit safe access and manoeuvrability. Adequate space should also be dedicated to handling samples obtained during the bronchoscopy. FB should be carried out in a fully equipped room with facilities for the administration of general anaesthesia. High power suction and a source of supplemental oxygen are essential. The following items should also be readily available: an anaesthetic machine, equipment for intubation and other adjuncts to protect the airways, resuscitation drugs and a full range of anaesthetic drugs. Back-up equipment should also be available to the bronchoscopist in case of any malfunction (light bulbs, suction apparatus, etc.). Minimal mandatory monitoring includes electrocardiography (ECG), pulse oximetry, noninvasive blood pressure and capnography (if the child is intubated). Although bronchoscopy can be performed with a bronchoscope and a light source, a video recording system shortens the procedure, allows immediate review of the findings and is very helpful in discussing the findings with the parents or referring physician, and is thus the preferred option.

The recovery area must allow privacy to the patient, but must be equipped with a supply of oxygen and full resuscitation equipment. Until full recovery, the patient should be continuously monitored by appropriately trained staff. 
Table 4.-Paediatric flexible bronchoscopes

\begin{tabular}{|c|c|c|c|c|c|}
\hline Maximum diameter & Working channel $^{\top}$ & Working length & Tip deflection & Field of vision & Depth of vision \\
\hline $2.2 \mathrm{~mm}$ & Not present & $550 \mathrm{~mm}$ & $\begin{array}{l}\text { Up } 160^{\circ} \\
\text { Down } 90^{\circ}\end{array}$ & $75^{\circ}$ & $2-50 \mathrm{~mm}$ \\
\hline $2.8 \mathrm{~mm}$ & $1.2 \mathrm{~mm}$ & $550 \mathrm{~mm}$ & $\begin{array}{c}\text { Up } 180^{\circ} \\
\text { Down } 130^{\circ}\end{array}$ & $95^{\circ}$ & $2-50 \mathrm{~mm}$ \\
\hline $3.5 \mathrm{~mm}$ & $1.2 \mathrm{~mm}$ & $600 \mathrm{~mm}$ & $\begin{array}{c}\text { Up } 180^{\circ} \\
\text { Down } 130^{\circ}\end{array}$ & $95^{\circ}$ & $3-50 \mathrm{~mm}$ \\
\hline $3.6 \mathrm{~mm}$ & $1.2 \mathrm{~mm}$ & $550 \mathrm{~mm}$ & $\begin{array}{c}\text { Up } 180^{\circ} \\
\text { Down } 130^{\circ}\end{array}$ & $120^{\circ}$ & $3-50 \mathrm{~mm}$ \\
\hline $4.9 \mathrm{~mm}$ & $2.2 \mathrm{~mm}$ & $600 \mathrm{~mm}$ & $\begin{array}{c}\text { Up } 180^{\circ} \\
\text { Down } 130^{\circ}\end{array}$ & $100^{\circ}$ & $3-50 \mathrm{~mm}$ \\
\hline $5.0 \mathrm{~mm}$ & $2.2 \mathrm{~mm}$ & $550 \mathrm{~mm}$ & $\begin{array}{c}\text { Up } 180^{\circ} \\
\text { Down } 130^{\circ}\end{array}$ & $120^{\circ}$ & $3-50 \mathrm{~mm}$ \\
\hline $3.8^{\#}$ & $1.2 \mathrm{~mm}$ & $600 \mathrm{~mm}$ & $\begin{array}{c}\text { Up } 180^{\circ} \\
\text { Down } 130^{\circ}\end{array}$ & $120^{\circ}$ & $3-100 \mathrm{~mm}$ \\
\hline $4.9 \mathrm{~mm}^{\#}$ & $2 \mathrm{~mm}$ & $600 \mathrm{~mm}$ & $\begin{array}{c}\text { Up } 180^{\circ} \\
\text { Down } 130^{\circ}\end{array}$ & $120^{\circ}$ & $3-50 \mathrm{~mm}$ \\
\hline $5.3 \mathrm{~mm}^{\#}$ & $2 \mathrm{~mm}$ & $600 \mathrm{~mm}$ & $\begin{array}{c}\text { Up } 180^{\circ} \\
\text { Down } 130^{\circ}\end{array}$ & $120^{\circ}$ & $3-100 \mathrm{~mm}$ \\
\hline
\end{tabular}

\#: Videobronchoscope; ${ }^{\circ}$ : mm of maximum diameter.

\section{Personnel}

The minimum personnel involved during bronchoscopy performed under sedation with local anaesthesia are the bronchoscopist, an adequately trained nurse, and another trained person who is responsible for administration of sedation and for monitoring of the patient. When the procedure is performed under general anaesthesia, the administration of drugs and monitoring is the responsibility of the anaesthetist, supported by appropriately trained personnel.

\section{Equipment}

The instruments available today are all much the same in terms of the quality of the fibreoptics, but vary in terms of the length and diameter of the instruments and suction channel. Examples of the various types of paediatric flexible bronchoscopes commonly used are listed in table 4 . In general, the smallest bronchoscope available should be used, in order to minimise blockage of the airway, unless an endobronchial biopsy is to be performed, when there is an argument for the use of the instrument with the biggest available biopsy channel, provided it is safe for the child. The manufacturers often describe the bronchoscope by the diameter of the tip. However, this is not always the maximum diameter of the bronchoscope. It is essential to be aware of this difference because the flexible bronchoscope is used increasingly in paediatric intensive care and often passed through an endotracheal tube or used as an aid to intubation [55]. If the flexible bronchoscope is to be passed through an endotracheal tube, the recommended difference in diameter is at least $1 \mathrm{~mm}$ so that the instrument can move inside the tube without getting stuck or the bronchoscope being damaged. The correct diameter of the flexible bronchoscope for paediatric use depends on the diameter of the child's cricoid cartilage [56], which is the narrowest point in the larynx. It is assumed that there must be at least a $2 \mathrm{~mm}$ difference between the gauge of the bronchoscope and the diameter of the larynx in order to ensure that FB can be performed safely. In infants and children, the most frequently used instruments are those with an outside diameter of 2.8, 3.5 and $3.6 \mathrm{~mm}$. From about the age of $6 \mathrm{yrs}$, instruments with larger diameters $(4.9 \mathrm{~mm})$ can be used, ultimately arriving at the bronchoscope used in adults $(6 \mathrm{~mm})$ by the time the child has reached puberty.

\section{Mobile bronchoscopy unit}

A mobile bronchoscopy unit permits the procedure to take place in any part of the hospital. A mobile cart needs to be equipped with a bronchoscope, light source, ECG monitor and a pulse oxymeter, video equipment and a suction device. The basic accessories (forceps, brushes, mucus traps etc.) should also be stored in the cart [57]. The basic resuscitation equipment (endotracheal tubes, laryngoscopes, suction catheters, ventilation bag) should either be stored in the bronchoscopy cart, or be immediately available on a separate trolley. However mobility and safety are not the same thing; the mobile unit should only be used in an environment where the safety of the child can be guaranteed at all times.

\section{Equipment storage area}

Flexible bronchoscopes are expensive and fragile instruments that require delicate handling and storage to guarantee their reliable function for the maximum period of time [57]. Flexible bronchoscopes should always be stored hanging in a straight vertical position to prevent development of unwanted curves of the shaft. A dedicated storage cabinet is essential to avoid contamination. The cabinet should be easy to clean, and preferably no other equipment should be stored with the bronchoscopes, to avoid damage or contamination to the instruments. It should be noted that flexible bronchoscopes should never be stored in an area routinely exposed to X-rays as this may damage the fiberoptic system. The accessories or any other bronchoscopy-related material for example forceps, specimen, pots etc. should be stored in the procedure room.

\section{Cleaning and disinfection}

\section{Cleaning and disinfection area}

Disassembling and cleaning of the bronchoscope is a delicate procedure that carries a risk of infection. Hence all 
cleaning-related manipulation should be done in an area separate from the bronchoscopy room and all usual infection precautions should be followed [57-59]. Appropriate measures should be taken to prevent spread of infection from patient to patient, from the environment to the patient, or from the patient to staff. Reasons for outbreaks of infections or pseudo-infections include inadequate cleaning and disinfection procedures, contamination of endoscopes by an automated washer/disinfector, contamination of accessory equipment (e.g. the brushes used to clean the bronchoscope channels), or a damaged endoscope [60]. Disinfection of flexible instruments may be difficult because of their complex channel and valve systems. Bronchoscopes should be regularly tested for leaks before cleaning to prevent permeation of any fluids into the optical system. If a leak is detected, the bronchoscope should no longer be immersed in a disinfectant, but should only be gas sterilised. If the instrument is damaged, it should be returned to the manufacturer for repair.

\section{Cleaning}

Of all infection control measures, thorough cleaning of the equipment is of the greatest importance. Immediately after use, the suction channel should be rinsed with water or saline to remove blood, tissue, and secretions. As soon as possible, mechanical cleaning, i.e. wiping of the outside of the bronchoscope and brushing of all channels with a detergent solution should be performed to prevent drying of secretions. Subsequently, the outside of the endoscope and the suction channel should be extensively rinsed with high-quality tap water and then dried by wiping with dry gauze and by suctioning. The removed and disassembled suction valve should be cleaned with a brush and detergent solution thoroughly, then rinsed and dried. Nondisposable accessories also require meticulous cleaning as soon as possible after the procedure. Reliable cleaning of items like biopsy forceps cannot be achieved without the use of an ultrasonic cleaner. Cytology brushes are disposable and should not be reused. Additional items of equipment like cameras, remote video controllers, light sources, and procedure carts should be regularly wiped with $70 \%$ alcohol.

\section{Disinfection}

After each examination, and before re-use, disinfection of the bronchoscope, aiming at the elimination of all organisms and viruses and of most bacterial and fungal spores, must be performed. Two per cent alkaline glutaraldehyde is the disinfectant of choice for flexible endoscopes: immersion for $20 \mathrm{~min}$ is considered sufficient to kill virtually all pathogens surviving on a well-cleaned bronchoscope [61]. As efficacy of any disinfecting or sterilising agent can only be assumed when microorganisms are exposed directly to the agent, increasing the period of disinfection does not compensate for inadequate cleaning. Glutaraldehyde and other disinfecting agents may be extremely irritating to the airway mucosa. Thus, disinfection must be followed by adequate rinsing of the instruments with sterile deionized water to remove all traces of the disinfectant. Subsequently, the insertion tube should be wiped and the channel and the suction valve rinsed with $70 \%$ alcohol and then dried. Alcohol is not only a powerful antimycobacterial agent, but also facilitates drying. Finally, the bronchoscope should be stored in a clean environment. Automated washer/disinfectors do not clean or disinfect endoscopes more thoroughly than can be achieved by hand.
Meticulous cleaning by hand must therefore precede the use of any of these machines. Automated disinfecting, however, reduces exposure of staff not only to contaminated equipment, but also to disinfectants, and may thus prevent sensitisation to aldehydes [62]. There is a need to disinfect the automated machine itself to prevent bacterial colonisation. Formation of biofilms has been described in automated washer/disinfectors; this may result in repeated contamination of endoscopes [63]. Periodically, samples obtained from the suction channel of the bronchoscope should be sent to the microbiological lab to exclude contamination.

\section{Sterilisation}

Sterilisation means the complete elimination of all viable organisms, including fungal spores. Flexible endoscopes are damaged by conventional heat sterilising methods. Gas sterilisation with ethylene oxide at temperatures $<55^{\circ} \mathrm{C}$ is safe, but not always practical because of the extended time needed to complete the sterilisation process. Furthermore, the recommended aeration time of $10-12 \mathrm{~h}$ severely restricts the availability of the bronchoscope. Thorough cleaning and drying of the bronchoscope must precede gas sterilisation. Damaged endoscopes have to be gas sterilised, as soaking the instrument will cause further damage. Even after a $30 \mathrm{~min}$ exposure to $2 \%$ glutaraldehyde the spring-operated suction valves may remain contaminated; thus, it is suggested that removable, heat-stable parts like suction valves should be steam autoclaved after cleaning [64]. Nondisposable accessories should be steam sterilised, if applicable. A biopsy forceps should always be sterilised. The manufacturers' guidelines should always be consulted and adhered to.

\section{Summary and conclusions}

Paediatric flexible bronchoscopy is an increasingly important investigation, allowing the possibility of performing diagnostic tests deep in the airway. It is a safe procedure, provided that the child is properly prepared, and when both sedation/anaesthesia and the procedure itself is performed by skilled and trained personnel. The range of pathology encountered is very different from that in adults, and thus the investigator should be trained to European standards in Paediatric Pulmonology. In the future colleagues should be encouraged to take the opportunity offered by diagnostic bronchoscopy to increase understanding of the basic pathophysiology of lung diseases.

\section{References}

1. Wood RE, Fink RJ. Applications of flexible fiberoptic bronchoscopes in infants and children. Chest 1978; 73: 737-740.

2. Wood RE. Spelunking in the pediatric airways: explorations with the flexible fiberoptic bronchoscope. Pediatric Clin North Am 1985; 31: 785-799.

3. Barbato A, Magarotto M, Crivellaro M, et al. The use of pediatric bronchoscope, flexible and rigid, in 51 European Centres. Eur Respir J 1997; 10: 1761-1766.

4. British Thoracic Society guidelines on diagnostic flexible bronchoscopy. Thorax 2001; 56: Suppl. I, 1-121.

5. De Blic J. Bronchoscopy. In: Greenough A, Roberton NRC, Milner AD, eds. Neonatal Respiratory Disorders. London, Arnold, 1996; pp. 89-96.

6. Cokugras H, Akcakaya N, Seckin I, Camcioglu Y, Sarimurat N, Aksoy F. Ultrastructural examination of bronchial biopsy 
specimens from children with moderate asthma. Thorax 2001; 56: 25-29.

7. Brownlee KG, Crabbe DC. Pediatric bronchoscopy. Arch Dis Child 1997; 77: 272-275.

8. Payne DNR, Adcock IM, Wilson NM, Oates T, Scallan M, Bush A. Relationship between exhaled nitric oxide and mucosal eosinophilic inflammation in children with difficult asthma, after treatment with oral prednisolone. Am J Respir Crit Care Med 2001; 164: 1376-1381.

9. Payne DN, Rogers AV, Adelroth E, et al. Early thickening of the reticular basement membrane in children with difficult asthma. Am J Respir Crit Care Med 2003; 167: 78-82.

10. Wood RE. Flexible bronchoscopy in children. In: Hilman $\mathrm{BC}$, ed. Pediatric Respiratory Disease: Diagnosis and Treatment. Philadelphia, Saunders WB, 1998; pp. 111-116.

11. Schellhase DE, Tamez JR, Menendez AA, Morris MG, Fowler GW, Lensing SY. High fever after bronchoscopy and bronchoalveolar lavage in noncritically ill immunocompetent children. Pediatr Pulmonol 1999; 28: 139-144.

12. Holinger LD. Congenital laryngeal anomalies. In: Holinger LD, Lusk RP, Green CG, eds. Pediatric Laryngology \& Bronchoesophagology. Philadelphia, Lippincott-Raven 1997; pp. 137-164.

13. Nussbaum E, Maggi JC. Laryngomalia in children. Chest 1990; 98: 942-944.

14. Fitch PS, Brown V, Schock BC, Taylor R, Ennis M, Shields MD. Chronic cough in children: bronchoalveolar lavage findings. Eur Respir J 2000; 16: 1109-1114.

15. Martinot A, Closset M, Marquette $\mathrm{CH}$, et al. Indications for flexible versus rigid bronchoscopy in children with suspected foreign-body aspiration. A J Respir Crit Care Med 1997; 156 : 1017-1019.

16. Mahut B, de Blic J, Le Bourgeois M, Beringer A, Chevalier JY, Scheinmann P. Partial and massive lung lavage in an infant with severe pulmonary alveolar proteinosis. Pediatr Pulmonol 1992; 13: 50-53.

17. Slattery DM, Waltz DA, Denham B, O'Mahony M, Greally P. Bronchoscopically administred recumbinant human DNase for lobar atelectasis in cystic fibrosis. Pediatr Pulmonol 2001; 31: 383-388.

18. Fan L, Sparks L, Fix E. Flexible fiberoptic endoscopy for airway problems in the pediatric intensive care unit. Chest 1988; 93: 556-560.

19. Schellhase DE, Fawcett DD, Schutze GE, Lensing SY, Tryka AF. Clinical utility of flexible bronchoscopy and bronchoalveolar lavage in young children with recurrent wheezing. J Pediatrics 1998; 132: 312-318.

20. de Blic J, Midulla F, Barbato A, et al. Bronchoalveolar lavage in children. Eur Respir J 2000; 15: 217-231.

21. Payne D, McKenzie SA, Stacey S, Misra D, Haxby E, Bush A. Safety and ethics of bronchoscopy and endobronchial biopsy in difficult asthma. Arch Dis Child 2001; 84: 423-426.

22. Bush A, Pohunek P. Brush biopsy and mucosal biopsy. Am J Respir Crit Care Med 2000; 162: 518-522.

23. Whitehead B, Scott JP, Helms P, et al. Technique and use of transbronchial biopsy in children and adolescents. Pediatr Pulmonol 1992; 12: 240-246.

24. Scott JP, Higenbottam TW, Smyth RL, et al. Transbronchial biopsies in children after heart-lung transplantation. Pediatrics 1990; 86: 698-702.

25. Fan LL, Kozinetz CA, Wojtezak HA, Chatfield BA, Cohen AH, Rothenberg SS. Diagnostic value of transbronchial, thoracoscopic, and open lung biopsy in immunocompetent children with chronic interstitial lung disease. J Pediatr 1997; 131: 565-569.

26. Mullins D, Livne M, Mallory GB Jr, Kemp JS. A new technique for transbronchial biopsy in infants and small children. Pediatr Pulmonol 1995; 20: 253-257.

27. Azizkhan RG, Lacey SR, Wood RE. Acquired symptomatic bronchial stenosis in infants: successful management using and argon laser. J Pediatr Surg 1990; 25: 19-24.
28. Bagwell CE. $\mathrm{CO}_{2}$ laser excision of paediatric airway lesions. J Pediatr Surg 1990; 25: 1152-1156.

29. Bramson RT, Sherman JM, Blickman JG. Pediatric bronchography performed through the flexible bronchoscope. Eur J Radiol 1993; 16: 158-161.

30. Finer NN, Muzyka D. Flexible endoscopic intubation of the neonate. Pediatr Pulmonol 1992; 12: 48-51.

31. Nakamura CT, Ripka JF, McVeigh K, Kapoor N, Keens TG. Bronchoscopic instillation of surfactant in acute respiratory distress syndrome. Pediatr Pulmonol 2001; 31: 317-320.

32. Wood RE, Lacey SR, Azizkhan RG. Endoscopic management of large, postresection bronchopleural fistulae with methacrylate adhesive (Super Glue). J Pediatr Surg 1992; 27 : 201-202.

33. Wood RE. Pitfalls in the use of flexible bronchoscope in pediatric patients. Chest 1990; 97: 199-203.

34. Cokugras H. Authors reply. Thorax 2003; 58: 187.

35. Sly PD. An Associate Editor's view. Thorax 2003; 58: 187-188.

36. Royal College of Paediatrics and Child Health. Guidelines for the ethical conduct of medical research involving children. Arch Dis Child 2002; 82: 177-182.

37. Bush A. Guidelines for the ethical conduct of medical research involving children. Arch Dis Child 2000; 83: 370.

38. Bush A, de Jongste JC, Carlsen K-H. Ultrastructural examination of bronchial specimens from children with moderate asthma. Thorax 2003; 58: 187.

39. McShane D, Davies JC, Davies MG, Bush A, Geddes DM, Alton EWFW. Airway surface $\mathrm{pH}$ in subjects with cystic fibrosis. Eur Respir $J$ 2003; 21: 37-42.

40. Shaw CA, Kelleher AA, Gill CP, Murdock LJ, Stables RH, Black AE. Comparison of the incidence of complications at induction and emergence in infants receiving oral atropine versus no premedication. Br J Anaesthesia 2000; 84: 174-178.

41. Klu PL, Egger M. Topical lidocaine exaggerated laryngomalacia during flexible bronchoscopy. Am J Respir Crit Care Med 2000; 161: 147-151.

42. Committee on drugs, section on anaesthesiology. Guidelines for the elective use of conscious sedation, deep sedation and general anaesthesia in pediatric patients. Pediatrics 1985; 76: 317-321.

43. Raine J, Warner JO. Fiberoptic bronchoscopy without general anesthetic. Arch Dis Child 1991; 66: 481-484.

44. Krauss B, Green SM. Sedation and analgesia for procedures in children. New Engl J Med 2000; 342: 938-945.

45. Malviya S, Voepel-Lewis T, Tait AR. Adverse events and risk factors associated with the sedation of children by nonanaesthesiologist. Anaesth Analg 1997; 85: 1207-1213.

46. Garcia J, Roure P, Hayem C, Dupont D. Endoscopie bronchique sous anesthesie locale et douleur chez l'enfant: interet du melange protoxyde d'azote-oxygene [local anaesthesia for flexible bronchoscopy: role of a mixture of nitrous oxide and oxygen]. Rev Mal Respir 1998; 15: 179-183.

47. Smith AR, Bowlay AR, Heaf LJ, Smyth RL. The laryngeal mask in fiberoptic bronchoscopy. Arch Dis Child 1996; 75: 344-355.

48. Chopra V, Bovill JG, Spierdijk J. Accidents near accidents and complications during anaesthesia. Anaesthesia 1990; 45: 3-6.

49. Gibson NA, Coutts JA, Paton JY. Flexible bronchoscopy under 10 kg. Respir Medicine 1994; 88: 131-134.

50. Schnapf B. Oxygen desaturation during FOB in pediatric patients. Chest 1991; 3: 591-594.

51. Slonim AD, Ognibene FP. Amnestic agents in pediatric bronchoscopy. Chest 1999; 11: 1802-1808.

52. Picard E, Schlesinger Y, Goldberg S, Schwartz S, Kerem E. Fatal pneumococcal sepsis following flexible bronchoscopy in an immunocompromised infant. Pediatr Pulmonol 1998; 25: $390-392$.

53. Wagener JS. Fatality following fiberoptic bronchoscopy in a two year child. Pediatr Pulmonol 1987; 3: 197-199. 
54. Picard E, Schwartz S, Goldemberg S, Glick T, Villa Y, Kerem E. A prospective study of fever and bacteremia after flexible fiberoptic bronchoscopy in children. Chest 2000; 117: 573-577.

55. Arul A, Jacob R. A different under vision approach to a difficult intubation. Pediatric Anaesth 1999; 9: 260-261.

56. Schild JA. Relationship of laryngeal dimensions to body size and gestational age in premature, neonates and small infants. Laryngoscope 1984; 94: 1284.

57. Berringer EC. The care and cleaning of the flexible bronchoscope. Anesthesiol Clin North America 1999; 9: 35-42.

58. Prakash UBS. Does the bronchoscope propagate infections? Chest 1993; 104: 552-559.

59. Green CG, Eisenberg J, Leong A, Nathanson I, Schnapf BM, Wood RE. Flexible endoscopy of the pediatric airway. Am Rev Respir Dis 1992; 145: 233-235.

60. Eber E. Infection control in flexible fiberoptic bronchoscopy.
In: Barbato A, Landau LI, Scheinmann P, Warner JO, Zach $\mathrm{M}$, eds. The broncoscope-flexible and rigid in children Treviso, Italy, Arcari Editore, 1995; pp. 87-92.

61. Woodcock A, Campbell I, Collins JVC, et al. Bronchoscopy and infection control. Lancet 1989; iì: 270-271.

62. Gannon PFG, Bright P, Campbell M, O'Hickey SP, Burge PS. Occupational asthma due to glutaraldehyde and formaldehyde in endoscopy and $\mathrm{X}$ ray departments. Thorax 1995; 50: 156-159.

63. Uttley AH, Simpson RA. Audit of bronchoscope disinfection: a survey of procedures in England and Wales and incidents of mycobacterial contamination. J Hosp Infect 1994; 26: 301-308.

64. Gubler JGH, Salfinger M, von Graevenitz A. Pseudoepidemic of nontuberculous mycobacteria due to a contaminated bronchoscope cleaning machine: report of an outbreak and review of the literature. Chest 1992; 101: $1245-1249$. 